\title{
Simulation of Dose Assessment for Special Environmental Radioactivity Distribution Using Monte Carlo Technique
}

\author{
Kh. Allam \\ Nuclear Law department, Nuclear and Radiological Regulatory Authority (NRRA), Cairo, Egypt \\ Email: khaledazalam@yahoo.com \\ Received 15 April 2014; revised 20 May 2014; accepted 10 June 2014 \\ Copyright (C) 2014 by author and Scientific Research Publishing Inc. \\ This work is licensed under the Creative Commons Attribution International License (CC BY). \\ http://creativecommons.org/licenses/by/4.0/

(c) (i) Open Access

\begin{abstract}
Many researchers use the estimation method of exposure doses due to natural radioactivity adopted by UNSCEAR equation, which is based on an infinite plan source modeling. The results in most cases are acceptable within acceptable accuracy and error. However, in many cases, this approach cannot be applied e.g., for more complicated source geometry, composition, radioactivity distribution and so on. In previous situations, simulation and modeling are needed for exposure dose calculation to get more acceptable and accurate results. In the present work, modeling and recalculation of exposure dose rate are performed for an important previous published study about Hammam Pharaon. The study is selected because of its special physical characterization parameters and possible effects on Egyptian tourism. The effects of radionuclides distribution with soils and source composition, density, and geometry as recommended by NCRP 129 have been taken into consideration. The results for depth profile calculation show the conformation with the NCRP 129, which indicates a reduction in the free air exposure dose due to the fact that the above soil covered the active slab by $20 \%-25 \%$ for $1 \mathrm{~cm}$ cover-up to $95 \%-100 \%$ for $30 \mathrm{~cm}$ cover. In addition, the effect of density variation in dose rate is studied. A comparison with previous results has been performed.
\end{abstract}

\section{Keywords}

Dose Rate Calculation, Monte Carlo Simulation, Environmental Radioactivity

\section{Introduction}

The investigation of the radiological effects of the environmental radioactivity is mainly based on the study of

How to cite this paper: Allam, K. (2014) Simulation of Dose Assessment for Special Environmental Radioactivity Distribution Using Monte Carlo Technique. Open Journal of Modelling and Simulation, 2, 91-96.

http://dx.doi.org/10.4236/ojmsi.2014.23011 
the radionuclides concentration (natural and man-made) in the environment. The determination of the expected exposure dose rate depends considerably on the conversion factors, absorbed dose rate in air per specific activity of soil in $\mathrm{nGy} \cdot \mathrm{hr}^{-1}$ per $\mathrm{Bq} \cdot \mathrm{kg}^{-1}$ adopted by UNSCEAR [1]-[3]. The basic model's input parameters were soil composition, density, source geometry and the exposure calculation height.

The difference between the real-live parameters and model's input parameters led to some uncertainties in exposure dose calculation. The uncertainties usually are not very large. However, in the cases of high differences, the needs for remodeling become essential, especially for exposure dose calculation to establish radiation protection regulations.

This work aims to outline the limitations of UNSCEAR estimated equation and represent the difference between real life parameters and estimated parameters.

In this study, modeling and recalculation of exposure dose rate have been performed for the Hammam Pharaon (hot spring) area. The importance of the selected study area is arising from the special physical characterization (source term shape, radioactivity distribution, composition and density) in addition to the development of climatotherapy and balneotherapy there. Hammam Pharaon and many other places in Egypt open the field of medical tourism. The source term shape, radioactivity distribution, composition and density have been considered. In addition, those places are characterized by their high content of natural minerals. Hammam Pharaon is located on the east side of Gulf of Suez, about $250 \mathrm{~km}$ in the east direction from Cairo. It is formed from a group of hot sulfuric water springs. The spring water flows directly from the limestone mountain caves, forming a natural canal with 100 meter length along the seashore. The out-flow water with elevated levels of ${ }^{226} \mathrm{Ra}$ and its progenies radionuclides affect an area of 100 meter length by 20 meter width of the shore.

\section{Calculation Procedure}

For a uniformly distributed gamma-emitting radionuclide, the dose rate at any point $\mathrm{p}$ due to the isotope radioactivity in the infinitesimal volume $d V\left(\mathrm{dx} . \mathrm{dy}\right.$.dz) at any other point at a distance $R\left(R^{2}=\mathrm{X}^{2}+\mathrm{Y}^{2}+\mathrm{Z}^{2}\right)$ from point $\mathrm{p}$ as shown in Figure 1 is given by Equation (1).

$$
d \stackrel{o}{D}=A \Gamma \frac{e^{-\sum_{i} \mu_{i} r_{i}}}{R^{2}} d V
$$

where $\stackrel{o}{D}$ is the absorbed dose rate in Gy/sec, $A$ is the concentration of the isotope in $\mathrm{MBq} / \mathrm{m}^{3}, \Gamma$ is the specific gamma-ray emission in $(\mathrm{C} / \mathrm{kg}) \mathrm{m}^{2} / \mathrm{MBq} \cdot \mathrm{hr}, \mu_{\mathrm{i}}$, is the total attenuation coefficient with coherent scattering $\left(\mathrm{m}^{-1}\right)$. These parameters depend on the energy from the photon; $r_{i}$ is the gamma-ray travel distance in layer No. $\mathrm{i}$. $\mathrm{R}$ the total distance between the point source and the calculation point in meter. The dose rate at a point $\mathrm{p}$ due to the entire isotope in the sand is computed from all the infinitesimal volume elements [4].

$$
\stackrel{o}{D}=A \Gamma \int_{0}^{V} \frac{e^{-\sum_{i} \mu_{i} r_{i}}}{R^{2}} \mathrm{~d} V
$$

Equation (2) can be now rewritten as:

$$
\stackrel{o}{D}=A \Gamma g
$$

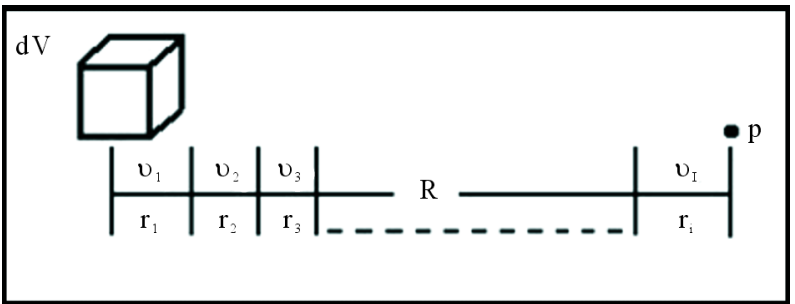

Figure 1. Diagram for calculating dose at pint $p$ from the gamma rays emitted from the volume element $\mathrm{dV}$ passing through $i$ media. 


$$
g=\int_{0}^{V} \frac{e^{-\sum_{i} \mu_{i} r_{i}}}{R^{2}} \mathrm{~d} V
$$

The factor $g$ is called the geometry factor that applies to a given point within a volume source. The geometrical factor takes into account the effects of both distance and energy absorption on the intensity of gamma photons as they penetrate the medium.

The analytical solution of dose rate Equation (2) in any volume source with any shape except a sphere is not found until now. In this work, Monte Carlo integration technique is used to solve Equation (4) for representing simulation models.

\section{Calculation Parameters}

\subsection{Source Geometry}

In this work as shown in Figure 2, there were two sources geometries, the mountain bedrock caves area and the seashore sand. First, the mountain bedrock is simulated as a parallelepiped with $20 \mathrm{~m}$ length, $20 \mathrm{~m}$ height and $0.2 \mathrm{~m}$ width. The mountain bedrock with highly contained radioactivity influence by the spring water was represented.

The second is the seashore sand area is simulated as a multilayer parallelepiped with $100 \mathrm{~m}$ length; $20 \mathrm{~m}$ width and $0.4 \mathrm{~m}$ height also represented the highly contained radioactivity area from the seashore affected by the spring water. The seashore height has been divided to eight layers of $0.05 \mathrm{~m}$ height. The calculations have made for $1 \mathrm{~m}$ above the seashore see Table 1 .

As shown in Figure 3, the calculations are done for every slab separately, considering the shielding effect of the upper slabs. The sum for all slabs has been then done then the mountain bedrock share is added. New software based on this model has been programmed using Pascal's programming language. It is very simple and gives a fast result with windows visual interface. It is applicable for daily work and environmental studies.

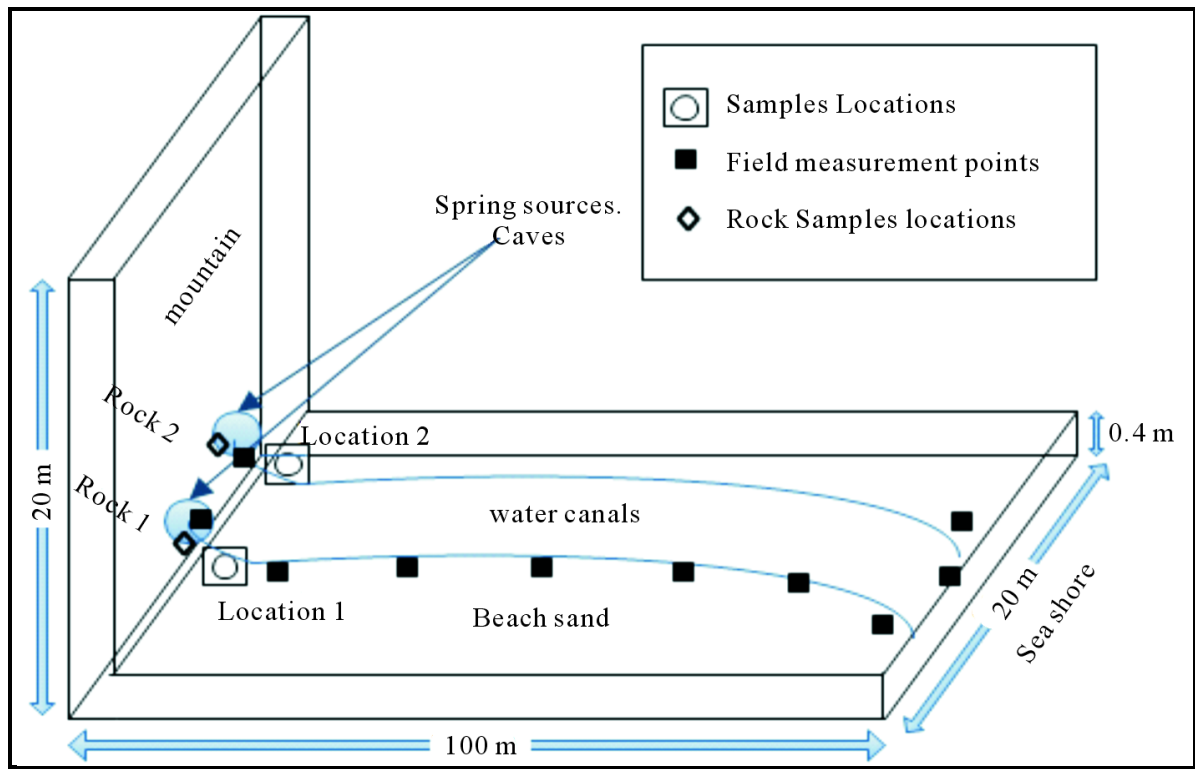

Figure 2. Represented a 3D view of the simulation model for Hammam Pharaon.

Table 1. This work source term geometry.

\begin{tabular}{ccc}
\hline Model & Ref. [1]-[3] & This work \\
\hline Seashore & Parallelepiped & $100 \times 20 \times 0.4$ \\
Mountain bedrock & Parallelepiped & $20 \times 20 \times 0.2$ \\
\hline
\end{tabular}




\subsection{Source Composition and Density}

The mountain bedrock composition has been taken as $100 \% \mathrm{CaCo}_{3}$ (limestone bedrock) with a density 2.0 $\mathrm{g} \cdot \mathrm{cm}^{-3}$. The seashore area composition has been taken as $100 \% \mathrm{SiO}_{2}$ with a density of $1.6 \mathrm{~g} \cdot \mathrm{cm}^{-3}$. Each model basic input parameters given in Table 2.

Above the seashore, an air have been simulated as the same source shape with an atomic composition of $75.5 \%$ $\mathrm{N}, 23.2 \% \mathrm{O}$ and $1.3 \%$ Ar and a density of $0.0012 \mathrm{~g} \cdot \mathrm{cm}^{-3}[1]$.

The total mass attenuation coefficients with coherent scattering $\left(\mathrm{cm}^{2} \cdot \mathrm{g}^{-1}\right)$ were calculated using XCOM program: Photon Cross Sections Database (NIST, XCOM). This software has a database that can be used to calculate photon cross sections for scattering, photoelectric absorption and pair production, as well as total attenuation coefficients, for any element, compound or mixture $(\mathrm{Z} \leq 100)$, at energies from $1 \mathrm{keV}$ to $100 \mathrm{GeV}$ [5].

\subsection{Experimental Data}

The experimental data has been taken from the above mentioned selected study of Hammam Pharaon site. The data are collected from two locations in Hammam Pharaon, location (1) and location (2) in Figure 3. The study focuses on ${ }^{226} \mathrm{Ra}$ concentration and its progenies measurements taking into consideration its elevation with depth. Two samples are taken from the mountain bedrock at caves entrances. Shore slides samples were collected from two locations of the active area of shore sand. Calculation based on UNSCEAR conversion factors show a radiation dose up to $5699 \mathrm{nSv} \cdot \mathrm{h}^{-1}$ [6]. It is more than 100 times the global average value $55 \mathrm{nGy} \cdot \mathrm{h}^{-1}$ [2].

In-situ dose-rate was measured and its value range between 8 and $15 \mu \mathrm{Sv} / \mathrm{h}$ with an average $11.5 \mu \mathrm{Sv} / \mathrm{h}$.

\section{Results and Discussion}

\subsection{Slab Results and Comparison}

The exposure dose rate for each slab is varying from 2.3 to $65.6 \mathrm{nSv} \cdot \mathrm{h}^{-1}$ for location 1 and from 5.2 to 180.2 $\mathrm{nSv} \cdot \mathrm{h}^{-1}$ for location 2 . While in previous study the dose rate varying from 184.0 to $1083.7 \mathrm{nSv} \cdot \mathrm{h}^{-1}$ for location 1 and from 423.1 to $1395.7 \mathrm{nSv} \cdot \mathrm{h}^{-1}$ for location 2.

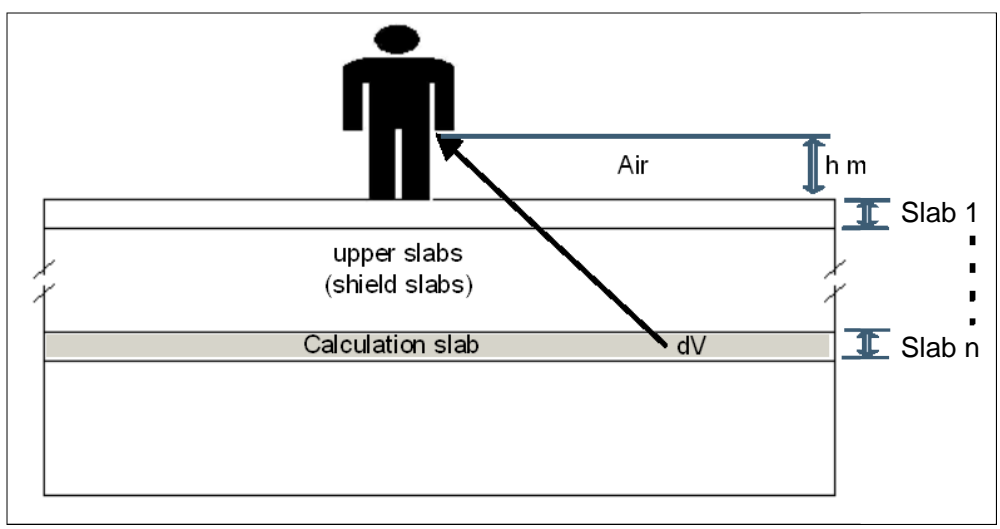

Figure 3. Simulation of slab calculation.

Table 2. Model parameter source term.

\begin{tabular}{ccccc}
\hline Soil composition & Ref. [1] & This work & Air composition & Ref. [1] \& this work \\
\hline $\mathrm{SiO}_{2}$ & $58.3 \%$ & $100 \%$ & $\mathrm{~N}_{2}$ & 75.5 \\
$\mathrm{Al}_{2} \mathrm{O}_{3}$ & $16.7 \%$ & -- & $\mathrm{O}_{2}$ & 23.2 \\
$\mathrm{Fe}_{2} \mathrm{O}_{3}$ & $8.3 \%$ & -- & $\mathrm{Ar}$ & 1.3 \\
$\mathrm{H}_{2} \mathrm{O}$ & $16.7 \%$ & -- & & 0.0012 \\
\hline
\end{tabular}


There are considerable differences between the estimated values of the exposure dose in the two studies. In the previous work, these values were calculated using the radioactivity isotope concentration in every slab in UNSCEAR equation and ignoring the shielding effect of the upper slabs [6]. In addition, the seashore (source) shape, composition, and density, which plays a considerable role in the exposure dose. In this work, we consider all the above-mentioned parameters in our estimation model for exposure dose. Besides, in this work also the importance of the mountain bedrock (Hammam Pharaon physical site) contribution in exposure dose is considered (see Figure 3). The calculation results are given in Table 3 and Table 4. The differences described above are due to site physical and geometrical properties, which are different from UNSCEAR 2000 model parameters [1].

The results of this work, shows a good agreement with the NCRP 129 results [7], which refer a reduction in the free air exposure dose due to above soil covered the active slab by $20 \%-25 \%$ for $1 \mathrm{~cm}$ cover-up to $95 \%$ $100 \%$ for $30 \mathrm{~cm}$ cover. In addition, the density difference plays an equally important role for exposure dose rate.

\subsection{The Result of Mountain Bedrock}

Now, if we add the mountain bedrock effect on the exposure dose calculation. The result values for exposure dose will change. In this work, the calculated exposure dose rate from the seashore and mountain bedrock ranged from 6.1 to $18.3 \mu \mathrm{Sv} \cdot \mathrm{h}^{-1}$ with an average $12.2 \mu \mathrm{Sv} \cdot \mathrm{h}^{-1}$. The experimentally measured values of the in-situ dose rate ranged between 8 and $15 \mu \mathrm{Sv} \cdot \mathrm{h}^{-1}$ with an average $11.5 \mu \mathrm{Sv} \cdot \mathrm{h}^{-1}$ [6]. This variation is due to the activity concentration variation from one location to another one and its distance from the hot spring cave entrance. Table 4 shows the calculated mountain bedrock exposure dose rate at $1 \mathrm{~m}$ above the ground.

This conclusion is adopted the previous work results, which indicate that the exposure dose in the first layer only is 3 times greater than the internationally recommended dose rate in site location 1 and 7 times greater than the recommended dose rate in location 2 [6]. As shown the model results are more comparable results with measured values than previous work.

Table 3. The calculated exposure dose rate at $1 \mathrm{~m}$ above the ground.

\begin{tabular}{|c|c|c|c|c|}
\hline \multirow{2}{*}{ Sample code } & \multirow{2}{*}{ Depth (cm) } & \multirow{2}{*}{${ }^{226} \mathrm{Ra}$ (Bq/kg) dry weight Ref. [4] } & \multicolumn{2}{|c|}{ Exposure dose rate $\mathrm{nGy} \cdot \mathrm{h}^{-1}$} \\
\hline & & & Ref. [4] & This work \\
\hline \multicolumn{5}{|l|}{ Location 1} \\
\hline $\mathrm{A} 1$ & $0-5$ & 431.0 & 184.0 & 65.6 \\
\hline B1 & $5-10$ & 785.0 & 335.3 & 35.7 \\
\hline $\mathrm{C} 1$ & $10-15$ & 867.0 & 370.3 & 17.4 \\
\hline D1 & $15-20$ & 1075.0 & 459.0 & 10.7 \\
\hline E1 & $20-25$ & 1212.0 & 517.1 & 6.4 \\
\hline $\mathrm{F} 1$ & $25-30$ & 1705.0 & 728.0 & 5.1 \\
\hline G1 & $30-35$ & 2538.1 & 1083.7 & 4.3 \\
\hline $\mathrm{H} 1$ & $35-40$ & 2267.0 & 968.0 & 2.3 \\
\hline Total & & & 4645.4 & 147.5 \\
\hline \multicolumn{5}{|l|}{ Location 2} \\
\hline A2 & $0-5$ & 991.0 & 423.1 & 180.2 \\
\hline $\mathrm{B} 2$ & $5-10$ & 2362.0 & 1008.5 & 124.4 \\
\hline $\mathrm{C} 2$ & $10-15$ & 3269.0 & 1395.7 & 74.8 \\
\hline D2 & $15-20$ & 3053.0 & 1303.7 & 34.1 \\
\hline E2 & $20-25$ & 2054.0 & 876.9 & 12.0 \\
\hline F2 & $25-30$ & 1619.0 & 691.1 & 5.2 \\
\hline Total & & & 5699 & 430.7 \\
\hline
\end{tabular}


Table 4. The calculated mountain bedrock exposure dose rate at $1 \mathrm{~m}$ above the ground.

\begin{tabular}{ccc}
\hline Sample code & ${ }^{226} \mathrm{Ra}(\mathrm{Bq} / \mathrm{kg})$ dry weight Ref. $[4]$ & ${\text { Exposure dose rate } \mathrm{nGy} \cdot \mathrm{h}^{-1}}^{-1}$ \\
Sample 1 & $10,781.3$ & 5911.3 \\
Sample 2 & $32,541.2$ & 17842.1 \\
& Average exposure dose & 11876.7 \\
\hline
\end{tabular}

The results show the difference between the real-live parameters and the adopted used parameters and their effect.

\section{Conclusions}

The results for the calculation of dose rate using the models proposed in this work are higher (up to 3 times) compared with the results obtained by UNSCEAR equation calculations [6]. In addition, in the previous study, the results were lower than its in-situ measurements and did not show an agreement with the NCRP 129 results which refer to a reduction in the free air exposure dose due to the fact that the above soil covered the active slab by $20 \%-25 \%$ for $1 \mathrm{~cm}$ cover-up to $95 \%-100 \%$ for $30 \mathrm{~cm}$ cover [7].

In spite of the simplicity of equation 2 for dose calculation approach, the calculated dose rate values based on this work model show an excellent agreement with the in-situ measurement values $\left(12.2 \mu \mathrm{Sv} \cdot \mathrm{h}^{-1}\right.$ to $\left.11.5 \mu \mathrm{Sv} \cdot \mathrm{h}^{-1}\right)$. This agreement clearly indicates the importance of source term self-absorption, geometry, and composition consideration and NCRP 129 recommendations [7], and the need of modeling and recalculations in case of multisource conditions.

\section{References}

[1] Saito, K. and Jacob, P. (1995) Gamma Ray Fields in the Air due to Sources in the Ground. Radiation Protection Dosimetry, 58, 29-45.

[2] UNSCEAR (1998) Sources, Effects, and Risks of Ionizing Radiation. United Nations Scientific Committee on the Effects of Atomic Radiation. Report to the General Assembly, with Annexes. United Nations Sales Publication E.88.IX.8, United Nations, New York.

[3] UNSCEAR (2000) Sources, Effects, and Risks of Ionizing Radiation. United Nations Scientific Committee on the Effects of Atomic Radiation. Report to the General Assembly, with Annexes. United Nations Sales Publication E.88.IX.8, United Nations, New York.

[4] Cember, H. and Johnson, T.E. (2009) Introduction to Health Physics. 4th Edition, McGraw-Hill, New York.

[5] XCOM, Photon Cross Sections Database, National Institute of Standards and Technology (NIST). http://physics.nist.gov/PhysRefData/Xcom/Text/XCOM.html

[6] El-Mongy, S.A., Ebaid, Y.Y., Diab, H.M. and El-Tahawy, M. (2004) Natural Enhanced Radium-226 at the Hammam Pharaon Hot Spring Area. Proceedings of the Environmental Physics Conference, 24-28 February 2004, Minya, 35-42.

[7] NCRP Report No. 129 (1999) Recommended Screening Limits for Contaminated Surface Soil and Review of Factors Relevant to Site-Specific Studies. National Council on Radiation Protection and Measurements, Bethesda. 
Scientific Research Publishing (SCIRP) is one of the largest Open Access journal publishers. It is currently publishing more than 200 open access, online, peer-reviewed journals covering a wide range of academic disciplines. SCIRP serves the worldwide academic communities and contributes to the progress and application of science with its publication.

Other selected journals from SCIRP are listed as below. Submit your manuscript to us via either submit@scirp.org or Online Submission Portal.
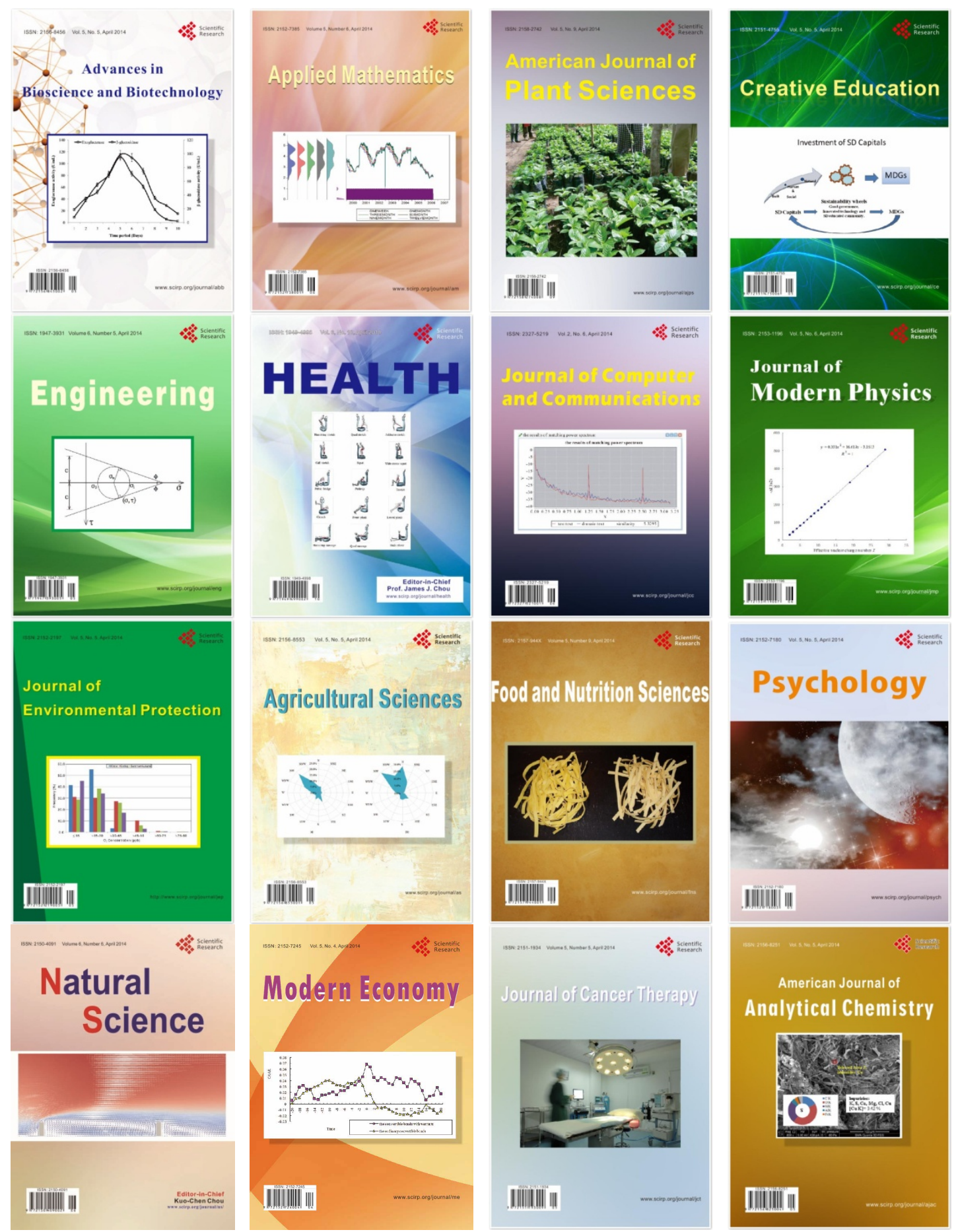